\title{
Drogadicção e adolescência: o "corpo do transbordamento"*1
}

\author{
Diana Borschiver Adesse*2 \\ Vera Lucia Alves dos Santos*3 \\ Marta Rezende Cardoso*4
}

Voltando nosso olhar para a adolescência atual, observamos significativa presença do fenômeno da drogadicção. Nesta situação clínica, as modalidades prioritárias de defesa são agenciadas por uma convocação do corpo e do ato, implicando a expulsão violenta de uma excitação interna desorganizadora, traumática. Investigar as determinações desse fenômeno - e cuja emergência tantas vezes se dá na travessia da infância à vida adulta - constitui o principal objetivo do presente artigo.

Palavras-chave: Adolescência, drogadicção, corpo, ato

*1 Artigo produzido durante o processo de Iniciação Científica do curso de Graduação em Psicologia de Diana Borschiver Adesse e Vera Lucia Alves dos Santos, sob a orientação da Profa. Dra. Marta Rezende Cardoso.

*2 Universidade Federal do Rio de Janeiro - UFRJ (Rio de Janeiro, RJ, Br).

${ }^{* 3}$ Universidade do Estado do Rio de Janeiro - UERJ (Rio de Janeiro, RJ, Br).

${ }^{*}$ Universidade Federal do Rio de Janeiro - UFRJ (Rio de Janeiro, RJ, Br). 
A adolescência é a expressão de um lugar de conflitualização violenta onde pulsões e defesas, investimentos narcísicos e objetais, se defrontam. Inscreve-se numa revivência da problemática edipiana infantil de onde emergem as fantasias pubertárias, dispondo desde então da potência que a genitalidade pubertária confere à criança que está se tornando adolescente.

Um dos grandes problemas que o sujeito adolescente tem de resolver, empenhado que está nas transformações impostas pela puberdade fisiológica, é o de viver essa experiência inédita e integrá-la sem perder o sentimento de continuidade de sua existência: em suma, mudar e permanecer o mesmo, adaptar-se à nova rodada de sua vida sem se tornar inteiramente estrangeiro a si mesmo. Porém, é bem uma experiência de estraneidade que o adolescente é levado a viver em relação ao seu próprio corpo, confrontado aos olhares que lhe indicam que não é mais o mesmo. Quando ultrapassado pela intensidade de suas próprias sensações, o adolescente corre o risco de perder a capacidade de se distinguir do outro, de diferenciar o dentro e o fora. A saída pode ser a expulsão violenta dessa excitação desorganizadora, traumática.

\section{A base traumática nas adiç̧ões: além do princípio do prazer?}

O sujeito adicto é definido por Gurfinkel (1993) como apegado, dependente, afeiçoado. Existem adiç̧ões aos mais diversos tipos de objeto: à droga, à comida, ao jogo, ao uso de pessoas. Um dos seus aspectos centrais é o que o referido autor denomina de funcionamento psíquico adictivo. Ao chamar a atenção para tal funcionamento, ele retira o foco do objeto-droga e o dirige à organização mental do sujeito.

Visando aprofundar a questão da drogadicção na adolescência, Gurfinkel (1993) aborda-a inicialmente a partir da problemática do 
princípio de prazer. Sob a regência deste princípio, a descarga de prazer é obtida por processos primários que empregam forças para obter o prazer e evitar o desprazer no psiquismo. Para Freud "prazer" e "desprazer" têm o seguinte equivalente quantitativo: o prazer é obtido pela redução da tensão psíquica, enquanto o desprazer se dá pelo aumento do nível de tensão. Essas duas dimensões envolvem processos distintos, pois buscar o prazer implica uma busca ativa que requer trabalho psíquico, sendo necessário sujeitar-se a possíveis frustrações, diferentemente da evitação do desprazer. Mas estamos aqui situados ainda no registro prazer-desprazer.

A busca pelo prazer imediato, de caráter absoluto, sem espera e sem mediação, aponta igualmente para importante precariedade no âmbito do princípio de realidade. Sob a regência deste princípio, a realização do desejo é incerta, indireta, necessita de trabalho psíquico e implica maior grau de tensão. De acordo com a vigência do princípio de realidade, a satisfação é obtida por meio do acionamento do processo secundário, cujo desenvolvimento impõe a tolerância às situações de tensão psíquica. O sujeito necessita suportar a frustração, a espera — inviável, por exemplo, nos casos de drogadicção. Nesta situação clínica, a capacidade de elaboração mostra-se precária.

Observamos, no entanto, que na toxicomania não há simplesmente uma busca ativa pelo prazer com efetivo trabalho psíquico, mas, sim, a busca de um "prazer" absoluto do qual os processos de representação e elaboração parecem radicalmente excluídos. Trata-se, no caso, de uma tendência à descarga absoluta da tensão interna. Esse modo de funcionamento psíquico não se encontra governado pelo princípio de prazer, tampouco podemos considerar que esse princípio teria sido substituído pelo princípio de realidade.

A adicção implica, dentre outros aspectos, uma tendência à repetição compulsiva de uma ação que se dirige a um mesmo objeto. Quando o ego apela ao registro do ato - modo primitivo de descarga de tensão interna — supomos que, na base desse recurso, haveria uma falha dos processos de representação e simbolização em relação a certos elementos. Conforme afirma Savietto (2010), tal falha seria um aspecto subjacente ao funcionamento psíquico dos sujeitos adictos, já que nesta patologia há a tendência do aparelho à descarga radical de excitações pela via do recurso ao ato.

Para analisar os aspectos desse funcionamento, pensamos que pode ser de grande importância recorrer à teoria freudiana, particularmente às contribuições de Freud a partir de 1920, quando ele propôs o segundo dualismo pulsional: o conflito entre pulsão de morte e pulsão de vida. Os esforços de Eros (pulsão de vida) são direcionados para conservar as substâncias vivas combinando-as em unidades cada vez maiores, enquanto Tanatos (pulsão de morte) trabalha para fazer essas unidades vivas retornarem ao estado inorgânico. Essas duas pulsões aparecem mescladas, 


\section{PRIMEIROS PASSOS}

podendo haver predomínio de uma sobre a outra, conforme os processos de ligação e desligamento das excitações ao nível psíquico. Com relação ao funcionamento mental do drogadicto, a descarga imediata das excitações pela via da compulsão à repetição, própria a um uso adictivo da droga, aponta para um desequilíbrio entre Eros e Tanatos, de modo que a ação da pulsão de morte está fortemente presente (Savietto, 2010).

Assim, partindo essencialmente dos desenvolvimentos de Freud desde o segundo dualismo pulsional, o modo de funcionamento psíquico do sujeito drogadicto encontra-se dominado por uma tendência que poderíamos situar "além do princípio do prazer". Complementando essas ideias, acrescentamos, com base ainda nas contribuições de Freud a partir de 1920, que o princípio de inércia é entendido como uma tendência à descarga até o nível zero de tensão, sendo tratado também como princípio de Nirvana. Não haveria na drogadicção um predomínio significativo do princípio de Nirvana, em função dessa tendência à eliminação radical de qualquer vivido de desprazer?

Segundo Gurfinkel (1993), tal predomínio, observado nas toxicomanias graves, diz respeito a um progressivo empobrecimento e eliminação dos processos de simbolização. Dessa forma, a tendência à eliminação radical do desprazer equivale a um ataque ao aparelho psíquico e seu funcionamento. Além disso, a intolerância ao desprazer pode levar, inclusive, à impossibilidade de qualquer busca por um prazer mediado, pois nesta busca seria preciso sujeitar-se a frustrações.

No funcionamento adictivo há, portanto, a presença significativa da pulsão de morte pois, subjacente a ele, há a ação de uma dimensão traumática, a irrupção de elementos irrepresentáveis. As contribuições de Lejarraga (apud Gaspar e col., 2011) nos ajudam a compreender a relação da pulsão de morte com a noção de trauma, retomada na obra freudiana a partir do segundo dualismo pulsional. De acordo com essa concepção, o traumático é entendido como aquilo que excede a capacidade de representação: trata-se de um excesso pulsional que ultrapassa a capacidade de simbolização do ego.

Sublinha Cardoso (2007) que os elementos traumáticos que não podem ser interiorizados como representação psíquica tendem a ser apresentados pela via do ato e do corpo, por meio de fenômenos marcados pela compulsão à repetição. Diante da insistência do traumático na clínica, Freud se volta para o mecanismo da compulsão à repetição. Esta pode ser considerada uma resposta extrema do ego quando se vê invadido por um pulsional mortífero que ultrapassa sua capacidade de ligação.

A compulsão à repetição é mecanismo marcante na drogadicção. Neste sentido, podemos supor que o recurso repetitivo ao abuso de drogas é utilizado como tentativa de resposta para aquilo que é irrepresentável. Assim, esse recurso pode ser utilizado diante de vivências traumáticas, tais como as que podem ser desencadeadas na adolescência. 
Conforme mostramos, no caso das adicções e, particularmente na drogadicção, há destruição dos processos de representação com a tendência à descarga imediata. Consideramos que o fenômeno da drogadicção se relaciona com a vivência da adolescência onde, como buscaremos mostrar no próximo tópico, o traumático se mostra através do sentimento de descontinuidade do corpo a partir do advento da puberdade.

\section{O traumático na base da adolescência}

Dentre os conflitos próprios da adolescência, destaca-se a revivência de dois conflitos básicos: o de separação/perda do objeto e o conflito edípico. A irrupção da puberdade, em um corpo até então infantil, produz inúmeras transformações psíquicas e corporais, configurando a travessia da adolescência. É justamente em meio a este turbilhão de experiências emocionais que o adolescente se encontra especialmente suscetível ao uso de drogas.

Antes de prosseguirmos, faz-se necessário apontar as considerações de Marty (2006) acerca da distinção entre as noções de puberdade e de "pubertário" (arrombamento pubertário). $\mathrm{O}$ autor considera que a puberdade estaria relacionada às mudanças corporais decorrentes da maturação do indivíduo, enquanto o pubertário seria um acontecimento psíquico imposto pelas mudanças do corpo biológico, ligado às transformações psíquicas, e com valor traumático.

O acontecimento pubertário é visto por Marty (2006) como um arrombamento no sentido em que o corpo é alvo de sentimentos de estranheza e vivido como objeto externo. O sofrimento dos adolescentes é fruto da violência própria a essa etapa da vida, a qual provoca ferida narcísica e verdadeiro traumatismo. O corpo é sentido "aos pedaços", e é necessário esforço para que essas novas sensações sejam assimiladas. $\mathrm{O}$ adolescente vive essa experiência como um bombardeio que o ataca, o atinge do exterior ou implode-o interiormente. Ele reage a essa vivência muitas vezes violentamente. Um exemplo dessa reação violenta é o uso de drogas, conforme procuraremos mostrar.

Gurfinkel (1993) cita a expressão de David Rosenfeld apontando que a droga poderia funcionar como uma "cola de má qualidade" (p. 133) frente a esse corpo fragmentado, aos pedaços. Este corpo púbere que se modifica rapidamente ameaça o sentimento de continuidade do sujeito e sua unidade narcísica. Neste sentido, a libido pubertária dá origem a uma ameaça interior que coloca em risco o equilíbrio narcísico-objetal e abre a possibilidade para o perigo de realização das fantasias edipianas pubertárias.

Marty (2006) destaca que o genital permite a interpretação do sexual infantil em um a posteriori. A puberdade seria como um limiar que precisa ser superado 
para que se constitua o traumatismo e possam surgir sensações inéditas, ligadas ao início da trajetória sexual e ao encontro com o objeto externo.

Para assimilar ao nível psíquico o seu novo corpo, o adolescente precisa renunciar aos objetos infantis. Mas para que isso ocorra é preciso que tenha elaborado adequadamente o luto das perdas infantis. As primeiras experiências de separação do objeto primário ocorrem na relação inicial mãe-bebê, e permitem ao sujeito se reconhecer separado dessa mãe. É a partir desta relação que são constituídos o corpo próprio e a unidade narcísica, e isso dependerá da qualidade do investimento materno.

Diversos autores destacam a relação que há entre a qualidade dessas primeiras experiências mãe-bebê e o trabalho do adolescente diante das transformações que aí ocorrem. Entretanto, para entendermos melhor este aspecto, primeiramente será necessário nos voltarmos para a questão da separação mãe-bebê e do processo de constituição do ego e do corpo próprio.

Como pontua, por exemplo, Maria Helena Fernandes (2002), a mãe deve investir libidinalmente no corpo da criança para poder escutá-lo e interpretá-lo. Diante de sensações desprazerosas, o bebê convoca a atenção da mãe, que deve ser capaz de apaziguar o desconforto que ele experimenta em seu corpo. Por meio da nomeação da mãe, constitui-se na criança a ideia de um corpo próprio e, portanto, independente de um outro. Diante da descoberta de sensações prazerosas em seu próprio corpo, surge a dimensão autoerótica, estágio onde a criança investe em si mesma, toma uma parte de si como objeto. Mas o autoerotismo só se constitui pela perda do objeto primário o qual garantiu a satisfação das necessidades iniciais. Daí a fundamental importância da qualidade de um investimento materno, sem o qual o bebê não alcançaria a experiência de prazer - este ficando, de certo modo, atrelado ao plano da necessidade.

$\mathrm{O}$ acesso ao corpo sexuado na adolescência supõe, portanto, a existência de um primeiro momento no qual as necessidades básicas foram satisfeitas. O outro é polo investidor que transforma o corpo biológico em corpo erógeno, corpo próprio, corpo simbolizado. Fernandes (2002) explica que o investimento da mãe é capaz de transformar o "corpo das sensações" em "corpo falado". É a mãe quem possibilitará a constituição do ego, da unidade narcísica e do sentimento de continuidade de si, essencial para uma boa passagem pela futura adolescência.

Fernandes (2002) reitera que a mãe deve obter prazer no contato com o corpo do bebê e em sua nomeação, possibilitando assim que este tome conhecimento da existência de seu próprio corpo, condição inicial para a futura concepção de um corpo como espaço unificado e diferenciado de um outro. Neste processo, está em jogo a constituição do narcisismo primário e, concomitantemente, a diferenciação eu-outro, aspectos fundamentais para a qualidade da travessia pela adolescência. 
As transformações que ocorrem no corpo adolescente, decorrentes da puberdade, fazem surgir um corpo genital pronto para o encontro com o objeto externo; entretanto, isso irá mobilizar vestígios do passado. Somente com uma vivência infantil de suficiente satisfação inicial e perda de objeto o adolescente será capaz de reajustar a imagem do seu corpo, o qual está em processo de modificação, e integrar suas transformações sem perder o sentimento de continuidade de si.

A qualidade dessas primeiras relações objetais tem fundamental importância no conflito de separação/perda dos objetos e da vida infantil, próprio à adolescência. $\mathrm{O}$ adolescente deve desinvestir os antigos objetos para se tornar um sujeito único e separado, mas para que isso ocorra é preciso que tenha sido suficientemente dependente deles. Cardoso (2006) aponta que o luto dos pais infantis a partir da ultrapassagem da questão edipiana representa uma das tarefas mais difíceis a serem realizadas na adolescência.

A revivência do complexo de Édipo à luz deste corpo genitalizado pode potencializar, em certos casos, os riscos de passagem ao ato, e toma uma dimensão assustadora. Os sentimentos incestuosos ganham mais força já que agora há um corpo capaz do encontro sexual. É exigido assim o efetivo abandono do objeto de desejo interditado para que novos objetos possam vir a ser investidos.

Emmanuelli (2008) aponta que a revivência edípica ocorre em sua dupla vertente, incestuosa e parricida, após o término do período de latência. Essa retomada leva em consideração a redescoberta do objeto sexual, restabelecendo suas ligações com os objetos infantis. Assim, a escolha de novos objetos de investimento trará consigo a marca dos objetos primários. Somem-se a isso as pulsões agressivas solicitadas nesse remanejamento — e tem-se a problemática da atuação como maneira de preservar o espaço próprio, frente a esse objeto que pode ser percebido como ameaçador.

Para Fernandes (2002), o adolescente necessita separar-se de seu objeto edipiano sem o perder. Mayer (1997) destaca neste sentido a importância da mãe que pode amar seu filho objetalmente, como um ser diferenciado. Essa mãe pode, em certa medida, tolerar que, com o intuito de se distanciar e substituí-la por um objeto de amor exogâmico, o adolescente a desvalorize como mulher. É preciso que a mãe suporte essa desvalorização para que o adolescente possa investir em outros objetos de amor, que não o edipiano.

Há também no processo adolescente um outro conflito: o enfrentamento com o pai. Em vez de buscar substituir o pai por outro homem ou objeto de amor exogâmico (como no caso materno), o adolescente necessita ocupar seu lugar. A difícil tarefa consiste em não somente superá-lo, mas também ficar com o que lhe pertence, e este movimento trará consigo a fantasia edipiana inconsciente de assassinato do pai.

A violência desencadeada pela reescritura do sexual infantil à luz do corpo genitalizado é, em geral, passível de elaboração. Em determinados sujeitos, essa 
vivência potencialmente desorganizadora vem desencadear um processo criativo que permite ao ego a transformação e elaboração desse traumático. Sobre este tópico, Cardoso (2006) destaca a tênue fronteira que separa o traumático "normal" (aquele que consegue uma via de elaboração) e o traumático "anormal" (o que extrapola os limites da representação). Assim, a adolescência comporta em si mesma um caráter traumático, porém, nas patologias tais como a drogadicção — que implicam significativa falência dos recursos egoicos e a consequente convocação violenta do corpo e do ato - revelam a presença de uma dimensão traumática cujo caráter é desestruturante. Nestes casos, estamos diante de um funcionamento psíquico marcado pelo excesso pulsional, e que nos remete às fronteiras da representação, o ego sendo confrontado com os limites entre a vida e a morte psíquicas. O sentimento de descontinuidade da adolescência é vivido aqui de maneira devastadora.

\section{Drogadicção e corpo do transbordamento: além da representação}

Tomando como objeto de nosso estudo o fenômeno da drogadicção na adolescência, ressaltamos a presença do traumático desestruturante, o qual estaria relacionado ao excesso pulsional e à incapacidade do ego de representar determinados elementos. Neste caso o corpo acaba sendo convocado pelo ego em prol de sua sobrevivência. Deste modo, esses elementos irrepresentáveis, não sendo interiorizados, acabam sendo exteriorizados, colocados para fora em forma de ato.

A convocação do corpo se configura como defesa primitiva e arcaica; trata-se de uma resposta defensiva extrema para fazer frente a essa força não ligada que invade o ego. Vê-se, portanto, que o corpo tem papel de destaque nesses casos já que, como nos mostra Cardoso (2007): "aquilo que não se faz representar tende a se apresentar como ato". As relações entre corpo e psiquismo já tinham sido apontadas por Freud a propósito do conceito de pulsão. Em "Os instintos e suas vicissitudes" (1915) Freud nos ensinará:

A pulsão nos aparecerá como sendo um conceito situado na fronteira entre o mental e o somático, como representante psíquico dos estímulos que se originam dentro do organismo e alcançam a mente, como uma medida de exigência feita à mente, no sentido de trabalhar em consequência de sua ligação com o corpo. (p. 127)

A partir do conceito de pulsão, Fernandes (2002) afirma que é possível falar de um corpo psicanalítico regido por dupla racionalidade: a do somático e a do psíquico. Essa dupla racionalidade é articulada pelo desejo inconsciente. O corpo psicanalítico, destaca a autora, seria construído pela alteridade, funcionando de acordo com a história do sujeito e obedecendo às leis do desejo inconsciente. 
Como indicamos anteriormente, com o segundo dualismo pulsional, Freud descreve a pulsão de morte como a pulsão sem representação, aquém da simbolização. Fernandes (2002) afirma que, ao explorar as relações entre o corpo e o psiquismo, é preciso ampliar as reflexões para além da lógica do recalcamento, para além do registro da representação. Introduz, então, as noções de corpo da representação e corpo do transbordamento. Nesta última, fica em evidência o aspecto de excesso pulsional e a condição de irrepresentável. O lugar do corpo na teoria freudiana e na clínica psicanalítica reflete e preserva traços dessa dupla incidência: a da representação e a do transbordamento.

"O corpo do transbordamento se refere ao sintoma corporal como uma descarga, como um excesso, que, atravessando o aparelho psíquico, não se organiza necessariamente a partir da lógica da representação" (Fernandes, 2002, p. 54). Entendendo a lógica do irrepresentável torna-se possível pensar na presença deste corpo do transbordamento em adolescentes drogadictos, pois nestes casos o não elaborado e o excesso traumático têm papel de destaque em suas organizações psíquicas. Observa-se, portanto, dentro desta lógica, a presença do corpo do transbordamento o qual busca a descarga absoluta, atuada.

A descarga psíquica radical que se dá na drogadicção é capaz de neutralizar os afetos e excluir os processos de elaboração, provocando assim uma deterioração das relações do sujeito consigo mesmo e com o outro. É nesse sentido que Pedinelli \& Rouan (apud Savietto, 2010) afirmam que a adicção provocaria uma dessexualização do corpo. Assim, além de se tratar de descarga direta, imediata, não processual, seria também uma descarga não libidinal.

$\mathrm{Na}$ drogadicção estariam envolvidas tanto a descarga de excitações psíquicas como também o encontro com sensações (autoestimuladas e essencialmente somáticas), pelas quais o drogadicto sente sua própria existência. Vale destacar que a fonte destas sensações é externa, afinal elas são provocadas pela droga (objeto exterior ao sujeito). $\mathrm{O}$ fato de essas sensações serem buscadas em uma substância exógena possibilita que o sujeito adicto julgue poder controlá-las, pois "escolhe" recorrer ao uso de tal substância. A estimulação e/ou o apaziguamento são obtidos por objetos ou situações materiais e controláveis, são trâmites e gestos concretos. Nestes casos, dois fatores contribuem para que a evacuação da tensão psíquica seja provisória e que por isso ocasione demanda constante de renovação das sensações: a fonte das sensações é externa e há falta de elaboração.

Como destaca McDougall, citada por Savietto (2010), nenhum objeto que pertence ao mundo real é capaz de reparar as falhas do mundo psíquico interno. Neste sentido, a autora conclui: "A busca de uma solução externa e somática para uma problemática interna e psíquica está fadada ao insucesso" (p. 31). Entretanto, é preciso ressaltar que apesar do comportamento compulsivo de ingestão de substâncias do drogadicto afetar os processos de elaboração, se constituindo até como 


\section{PRIMEIROS PASSOS}

antissimbolização pelo seu caráter de descarga radical de excitações, é possível vislumbrar aí uma reação ao estado de dor mental.

A partir do que foi abordado ao longo do texto, entendemos que a adolescência se configura como experiência potencialmente desencadeadora da emergência e possível dominância desse corpo do transbordamento, já que, como mostramos, ela comporta inevitavelmente uma dimensão traumática. Para tentar lidar com o arrombamento pubertário, frente ao qual os recursos psíquicos falham, a drogadicção, cuja emergência tantas vezes se dá na adolescência, pode constituir um modo de defesa extrema, paradoxalmente destrutiva, mas como tentativa de resposta, ainda que precária.

\section{Referências}

Cardoso, M. R. (Org.) (2006). Adolescentes. São Paulo: Escuta.

Cardoso, M. R. (2007, dez.). A impossível "perda" do outro nos estados limites: explorando as noções de limite e alteridade. Psicologia em Revista, Belo Horizonte, 13(2), 325-338.

Emmanuelli, M. (2008). A clínica da adolescência. In M. R. Cardoso \& F. Marty (Orgs.). Destinos da adolescência. Rio de Janeiro: 7Letras.

Fernandes, M. H. (2002). Entre a alteridade e a ausência: o corpo em Freud e sua função na escuta do analista. Percurso, 29, 51-64, $2^{\circ}$ semestre/2002.

Freud, S. (2006a). Os instintos e suas vicissitudes. Sobre a história do movimento psicanalítico, artigos sobre metapsicologia e outros trabalhos. In Edição Standard Brasileira das Obras Psicológicas Completas de Sigmund Freud (Vol. 14, pp. 123-144). Rio de Janeiro: Imago (Trabalho original publicado em 1915).

Freud, S. (2006b). Além do princípio de prazer. Além do princípio de prazer, psicologia de grupo e outros trabalhos. In Edição Standard Brasileira das Obras Psicológicas Completas de Sigmund Freud (Vol. 18, pp. 13-156). Rio de Janeiro: Imago (Trabalho original publicado em 1920).

Gaspar, F. L., Lorenzutti, P. S. \& Cardoso, M. R. (2011). Trauma e representação: estudo de um caso clínico. In M. R. Cardoso (Org.). Adolescentes. São Paulo: Escuta.

Gurfinkel, D. (1993). Introdução a uma abordagem psicanalítica da questão das drogas na adolescência. In Adolescência: abordagem psicanalítica. São Paulo: EPU.

Marty, F. (2006). Adolescência, violência e sociedade. Ágora, Rio de Janeiro, 9(1), 119-131.

Mayer, H. (1997). Adicciones: un mal de la posmodernidad: teoría, clínica, abordajes. Buenos Aires: Ediciones Corregidor.

Savietto, B. B. (2010). Drogadiç̧ão na juventude contemporânea: a "intoxicação" pelo outro. Tese de doutorado. Programa de Pós-graduação em Teoria Psicanalítica, Instituto de Psicologia, Universidade Federal do Rio de Janeiro, Rio de Janeiro. 


\section{Resumos}

(Drug addiction and adolescence: the "body of overflowing")

Drug addiction has become a major problem in adolescence today. In such addictions, primary modes of defense lead the body to act, a process that implies the expulsion of disruptive internal traumatic excitation. The aim of this paper is to examine the causes of this phenomenon that frequently arises in the transition from childhood to adulthood.

Key words: Adolescence, drug addictions, body, act

(Dépendance chimique et adolescence: le "corps du dépassement")

En tournant notre regard vers l'adolescence actuelle, nous pourrons y découvrir une présence expressive du phénomène de la dépendance chimique. Dans cette situation clinique, les modalités prioritaires de défense sont traitées par la convocation du corps et de l'acte, ce qui implique l'expulsion violente d'une excitation interne désorganisatrice, traumatique. Cet article a comme but d'examiner les déterminations de ce phénomène qui se produit si souvent lors du passage de l'enfance à l'âge adulte.

Mots clés: Adolescence, dépendance chimique, corps, acte

(Addicción a las drogas y adolescencia: el "cuerpo del trasbordamiento")

Volviendo nuestra mirada para la adolescencia contemporánea, observamos la presencia importante del fenómeno de la drogadicción. En esta situación clínica los modos prioritarios de defensa son negociados por la convocación del cuerpo y del acto, lo que implica la expulsión violenta de una excitación interna traumática perturbadora. El principal objetivo de este artículo es investigar las determinaciones de este fenómeno que suele aparecer en la travesía de la infancia a la edad adulta.

Palabras clave: Adolescencia, drogadicción, cuerpo, acto

\section{(Drogenabhängigkeit und Jugend: der "Körper des Überlaufens")}

Zurückblickend auf die aktuelle Jugend, beobachten wir eine bedeutsame Anwesenheit des Phänomens der Drogenabhängigkeit. In dieser klinischen Situation werden die bevorzugten Verteidigungsmodalitäten durch einen Aufruf des Körpers und der Aktes hervorgerufen, die zu einem gewaltsame Ausdruck einer verwirrenden, traumatischen inneren Aufregung führen. Die Untersuchung der Ausprägung dieses Phänomens - und dessen Not ergibt sicht oftmals im Übergang von der Kindheit zum erwachsenen Leben - ist das Hauptziel des vorliegenden Artikels.

Schlüsselwörter: Jugend, Drogenabhängigkeit, Akt, Körper 


\section{PRIMEIROS PASSOS}

Citação/Citation: Adesse, D. B., Santos, V. L. A. dos \& Cardoso, M. R. (2014, setembro). Drogadicção e adolescência: o "corpo do transbordamento". Revista Latinoamericana de Psicopatologia Fundamental, 17(3), 544-556.

Editor do artigo/Editor: Profa. Dra. Ana Cecília Magtaz

Recebido/Received: 26.3.2014/ 3.26.2014 Aceito/Accepted: 15.5.2014 / 5.1 5.2014

Copyright: (C) 2009 Associação Universitária de Pesquisa em Psicopatologia Fundamental/ University Association for Research in Fundamental Psychopathology. Este é um artigo de livre acesso, que permite uso irrestrito, distribuição e reprodução em qualquer meio, desde que o autor e a fonte sejam citados / This is an open-access article, which permits unrestricted use, distribution, and reproduction in any medium, provided the original author and source are credited.

Financiamento/Funding: Pesquisa financiada pela Fundação de Amparo à Pesquisa do Estado do Rio de Janeiro - Faperj e do Conselho Nacional de Desenvolvimento Científico e Tecnológico - $\mathrm{CNPq} /$ The research was funded by the Fundação de Amparo à Pesquisa do Estado do Rio de Janeiro - Faperj and Conselho Nacional de Desenvolvimento Científico e Tecnológico - CNPq.

Conflito de interesses/Conflict of interest: As autora sdeclaram que não há conflito de interesses

/ The author declares that has no conflict of interest

\section{Diana Borschiver Adesse}

Psicóloga pela Universidade Federal do Rio de Janeiro - UFRJ (Rio de Janeiro, RJ, Br); Bolsista da Fundação de Amparo à Pesquisa do Estado do Rio de Janeiro - Faperj (Rio de Janeiro, RJ, Br), para Iniciação Científica; Mestranda do Programa de Pós-Graduação em Teoria Psicanalítica da Universidade Federal do Rio de Janeiro - UFRJ (Rio de Janeiro, RJ, Br); Bolsista da Coordenação de Aperfeiçoamento de Pessoal de Nível Superior - Capes (Brasília, $\mathrm{DF}, \mathrm{Br})$.

Rua Professor Gastão Bahiana 111/302 - Copacabana

22071-030, Rio de Janeiro, RJ, Br

e-mail: dianaborschiver@gmail.com 


\section{Vera Lucia Alves dos Santos}

Psicóloga pela Universidade Federal do Rio de Janeiro - UFRJ (Rio de Janeiro, RJ, Br); Bolsista do Conselho Nacional de Desenvolvimento Científico e Tecnológico - CNPq (Brasília, DF, Br) para Iniciação Científica); Aluna e bolsista do Curso de Residência Multiprofissional em Saúde Mental na Universidade do Estado do Rio de Janeiro - UERJ/ SES-RJ (Rio de Janeiro, RJ, Br).

Rua J. J. Cowsert, 300, casa 27 21370-450 Rio de Janeiro, RJ, Br e-mail: vera_las@hotmail.com

\section{Marta Rezende Cardoso}

Psicóloga; Psicanalista; Doutora em Psicanálise e Psicopatologia Fundamental pela Universidade de Paris Diderot - Paris 7 (Paris, Fr); Professora Associada do Instituto de Psicologia da Universidade Federal do Rio de Janeiro - UFRJ (Rio de Janeiro, RJ, Br) (Programa de Pós-Graduação em Teoria Psicanalítica); Pesquisadora (bolsa de produtividade em pesquisa) do Conselho Nacional de Desenvolvimento Científico e Tecnológico - CNPq (Brasília, DF, Br); Pesquisadora da Associação Universitária de Pesquisa em Psicopatologia Fundamental (São Paulo, SP, Br).

Rua Gustavo Sampaio, 710/1805

22010-010 Rio de Janeiro, RJ, Br

e-mail: rezendecardoso@gmail.com 